\title{
KINETICS OF BIPEDAL LOCOMOTION DURING LOAD CARRYING IN CAPUCHIN MONKEYS
}

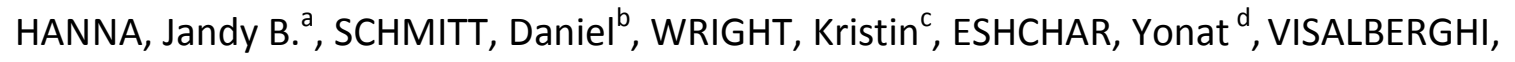
Elisabetta $^{\mathrm{e}}$, FRAGASZY, Dorothy ${ }^{\mathrm{d}}$

a Division of Biomedical Sciences, 400 N. Lee St., West Virginia School of Osteopathic Medicine, Lewisburg, WV 24901, USA; jhanna@osteo.wvsom.edu

${ }^{b}$ Department of Evolutionary Anthropology, 104 Biological Sciences Building, Campus Box 90383, Duke University, Durham, NC 27708, USA; daniel.schmitt@duke.edu

${ }^{\mathrm{C}}$ Department of Anatomy, Kansas City University of Medicine and Biosciences, Kansas City, MO 64106, USA; kwright@kcumb.edu

d Department of Psychology, 125 Baldwin St., University of Georgia, Athens, GA 30602, USA; yonat@uga.edu, doree@uga.edu

${ }^{\mathrm{e}}$ Unit of Cognitive Primatology and Primate Centre, Istituto di Scienze e Tecnologie della Cognizione, Consiglio Nazionale delle Ricerche via Aldrovandi 16b, 00197, Roma (RM), Italy; elisabetta.visalberghi@istc.cnr.it

Number of text pages including abstract: 16

Figures: 3

Tables: 4

\section{Corresponding author:}

Jandy B. Hanna

Biomedical Sciences Department

WVSOM

400 North Lee Street

Lewisburg, WV 24901

Phone: 304-647-6366

Email: jhanna@osteo.wvsom.edu 


\section{Abstract}

Facultative bipedalism during load transport in non-human primates has been argued to be an important behavior potentially leading to the evolution of obligate, extended limb bipedalism. Understanding the biomechanics of such behavior may lead to insights about associated morphology, which may translate to interpretation of features in the fossil record. Some populations of bearded capuchin monkeys (Sapajus libidinosus) spontaneously carry heavy loads bipedally during foraging activities. This study provides the first data on all three components of ground reaction force for spontaneous bipedalism during load carriage in a nonhuman primate. Five individual S. libidinosus (mean body mass $=2.4 \mathrm{~kg} \pm 0.96$ ) were videorecorded during bipedalism while carrying a stone $(0.93 \mathrm{~kg})$ under natural conditions. A force plate was embedded in the path of the monkeys. Spatiotemporal and force data for all three components of the ground reaction force were recorded for 28 steps. Capuchins exhibited a mean vertical peak force per total weight (Vpk) for the hindlimb of 1.19 (sd=0.13), consistent with those of unloaded capuchins in the laboratory and for other bipedal primates, including humans. Vertical force records suggest that capuchins, along with most nonhuman primates, maintain a relatively compliant leg during both unloaded and loaded locomotion. Like all other primates, loaded capuchins maintained laterally (outward) directed medio-lateral forces, presumably to stabilize side-to-side movements of the center of mass. Medio-lateral forces suggest that at near-running speeds dynamic stability diminishes the need to generate high lateral forces. Vertical force traces exhibited a measurable impact spike at foot contact in $85 \%$ of the steps recorded. An impact spike is common in human walking and running but has not been reported in other bipedal primates. This spike in humans is thought to lead to bone 
and cartilage damage. The earliest biped may have experienced similar impact spikes during bipedal locomotion, requiring compensatory behaviors or anatomical features.

Key words: biomechanics, locomotion, bipedalism, capuchin 


\section{Introduction}

The evolution of obligate bipedalism is seen as a hallmark of human evolution and a defining characteristic of hominins. Although the specific selective pressure or pressures that drove the evolution of upright walking remain unknown, many researchers over the past hundred years have evoked load carriage as an important factor in the origin and improvement of bipedalism (Hewes, 1961; Videan and McGrew, 2002; Preuschoft, 2004; Wall-Scheffler et al., 2007b; Watson et al., 2008; Watson et al., 2009; Watson et al., 2011; Carvalho et al., 2013). Even if load carriage was not a primary selective factor in the commitment to bipedal locomotion, it is widely seen as a reason that primates might have initially used bipedal stances with regularity and as part of the accrued advantage of upright locomotion after its initial development. Although some experiments have explored load carriage and human anatomy in an evolutionary context (Wang et al., 2002; Wang and Crompton, 2004; Duarte et al., 2012; Carvalho et al., 2013), no studies have examined the kinetics of bipedalism during load carriage in free-ranging primates. This study, on a group of free-ranging capuchin monkeys on a large private area of land in Piauí, Brazil, addresses this and provides the first published data on all three components of ground reaction force during bipedalism in capuchin monkeys.

Only a few living primate species regularly exhibit bipedal locomotion and only humans are obligate and exclusive bipeds. When sifaka (Propithecus) and gibbons (Hylobatidae) move on the ground they are obligated to move bipedally probably as a result of their unusual anatomy associated with leaping and brachiation (Stern, 1976; Tuttle et al., 1979; Tuttle, 1981; Vereecke et al., 2005; Wunderlich et al., 2014), although bipedalism represents a small portion of their locomotor repertoires (Gebo, 1987; Hunt, 1991). Other primates, including 
chimpanzees, bonobos, macaques, capuchins, and even baboons, frequently engage in bouts of bipedal locomotion, often in the context of foraging and load carriage (e.g. Cant, 1988; Hunt, 1991; Aerts et al., 2000; Fragaszy et al., 2004b).

Studying the mechanics of locomotion in facultative primate bipeds has produced important insight into understanding human evolution (for review see Schmitt, 2003; Berillon et al., 2011; Schmitt, 2012; D’Août et al., 2014; Daver et al., 2014; Pontzer et al., 2014). Some of these studies have focused specifically on the ground reaction forces during bipedalism and their implications for understanding the different mechanical strategies associated with propulsion and balance during different forms of bipedal walking. In the early and middle 1970s, Kimura and colleagues collected seminal data on all three components of ground reaction forces during bipedal locomotion in humans and nonhuman primates (Kimura et al., 1977) and revealed different types of bipedal patterns including the presence or absence of a two-peaked vertical force curve and the relative duration of braking and propulsive forces. Those data were followed by additional data from Reynolds (1985), Kimura (1985), Yamazaki et al. (1979) and Vereecke et al. (2006) that revealed patterns associated with the center of mass movements, development of bipedalism, and the effect of a compliant foot on ground reaction forces. In addition to these studies, Ogihara and colleagues $(2007 ; 2010)$ showed that force patterns of macaques trained over long periods to walk bipedally became more similar to those of human locomotion over time, suggesting that frequent bipedal walking modifies kinetic and kinematic patterns within the lifetime of an animal and presumably modifies the loading patterns on the limbs. 
However, until recently, no study had examined bipedal locomotion in capuchin monkeys. This represented an important gap in our knowledge because capuchins frequently and skillfully adopt bipedal walking, especially in the context of load carriage (Fragaszy et al., 2004b; Visalberghi et al., 2009b; Duarte et al., 2012). Demes and O'Neill (2013) provided the first data on vertical ground reaction forces in tufted capuchins (Sapajus sp. ${ }^{1}$ ) moving bipedally on a terrestrial substrate. They examined freely moving animals in a laboratory setting and reported on the magnitude and shape of the vertical force curve. They noted that, unlike humans during walking, tufted capuchins exhibited a single-peaked force curve indicative of mechanical running in which the center of mass did not oscillate like an upside down pendulum as in human walking, a pattern also seen in most other terrestrial, bipedal primates. Thus, it is argued, based on the mechanical definition, that capuchins move bipedally using a 'grounded running' gait, in which there is no aerial phase of the feet, but the whole body mechanics are similar to the spring-like running gait exhibited by humans (Demes and O'Neill, 2013). In addition, they reported that the vertical force traces "lack the impact spike that is characteristic of human walking and running with a prominent heel strike" (Demes and O'Neill, 2013: 80). The vertical impact spike associated with the change in momentum of the effective foot mass at heel strike (Chi and Schmitt, 2005; Lieberman et al., 2010) is not seen in most other traces reported for other primates during bipedalism (Kimura et al., 1977; Kimura, 1985; Vereecke et al., 2005; 2006; Ogihara et al., 2007; Berillon et al., 2013). All of these authors report a single or flat peak curve, even for some chimpanzees that exhibit a heel-strike. In

\footnotetext{
${ }^{1}$ Colonies of tufted capuchin monkeys held in the USA have recently been determined to be derived from species in the genus Sapajus, distinct from Cebus monkeys. See Duarte et al., 2012, Lynch Alfaro et al., 2012 and Wright et al., 2015, for details.
} 
contrast, recent work by Pontzer and colleagues (2014) suggests that some chimpanzees do exhibit an impact transient (or impact spike) during bipedal locomotion, although this cannot be linked specifically to heel-strike. Thus, it may be that in some limited circumstances primates that utilize spring-like mechanics to move bipedally may also exhibit an impact transient as suggested by Pontzer and colleagues (2014). Finally, regarding capuchin bipedalism, Demes and O'Neill (2013) did not provide information on braking-propulsive or medio-lateral forces during walking, although they did incorporate such information into their center of mass analysis that revealed a compliant, grounded running gait in tufted capuchins.

At least one tufted capuchin species (Sapajus libidinosus) exhibits bipedal locomotion on terrestrial substrates primarily when carrying food or stones that they use to crack nuts (Fragaszy et al., 2004a; Visalberghi et al., 2009a; 2013). These stones are often very heavy, representing a significant part of their body weight, and therefore these animals make an ideal model for studying the effect of load carriage. No such data on the force patterns of nonhuman primates during load carriage exist. This is in part because up until recently it has been difficult, if not impossible, to collect biomechanical data on nonhuman primates locomotion in the wild (see Schmitt, 2011 for review) where spontaneous, terrestrial bipedalism during load carriage occurs. While there are numerous studies on facultative bipedalism by nonhuman primates in a controlled setting (e.g. Kimura et al., 1977; Aerts et al., 2000; Nakatsukasa et al., 2004;

Vereecke et al., 2006; Ogihara et al., 2007; Vereecke and Aerts, 2008; Demes, 2011; Demes and O'Neill, 2013), including some focused on load transport (see Watson et al., 2011 for review), only two have examined primate load transport in the wild (Duarte et al., 2012; Carvalho et al., 2013), and neither from the perspective of the forces born by the limbs. There are, however, 
data available on the kinetics of load transport by humans that indicate that while ground reaction forces increase proportionately to the load carried (Tilbury-Davis and Hooper, 1999; Birrell et al., 2007) vertical peak forces do not change if calculated as a ratio to total mass of the system (i.e. body mass + load mass) (Tilbury-Davis and Hooper, 1999). These results, however, depend on the weight of the load relative to body weight and the distribution of the load and/or the manner in which it is carried, as differences in biomechanics and energetics correlate with differences in load distribution (Hsiang and Chang, 2002; Griffin et al., 2003; Birrell and Haslam, 2008; Majumdar et al., 2010; Watson et al., 2011; McGill et al., 2013). The largest ground reaction force effects of load transport on locomotion are seen when significant loads ( $10 \%-15 \%$ of body mass) are carried in both arms (e.g. Hsiang and Chang, 2002), likely because this style of load transport limits arm swing (e.g. Li et al., 2001; Umberger, 2008). When arm swing is limited due to anterior load carriage, peak braking and propulsive forces and medio-lateral forces are increased (e.g. Birrell et al., 2007; Birrell and Haslam, 2008). Finally, impact peaks are shown to increase with load carrying, likely because the load is over the striking foot (e.g. Hsiang and Chang, 2002; Birrell et al., 2007; Birrell and Haslam, 2008). The goals of this study are to determine the ground reaction force effects during load carrying by bipedal capuchins. We hypothesize that:

1) Load carrying capuchins will continue to exhibit a single-peaked vertical reaction force indicative of a grounded running gait,

2) Peak braking/propulsive forces and medio-lateral forces will be increased relative to non-load carrying, and 
3) Load carrying capuchins may occasionally exhibit an impact peak in the vertical force due to the added weight.

\section{Materials and methods}

The protocol for this study was approved by the University of Georgia IACUC and followed all applicable regulations for the humane treatment of animals in research. The ethical standards of this protocol were as stringent as the guidelines advocated by the Association for the Study of Animal Behavior (ASAB, 2012) and the International Primatological Society (IPS, 2015).

\section{Subjects and Site}

Tufted capuchins (Sapajus) are primarily quadrupedal primates, with a very generalized postcranial morphology (Fleagle, 2013). These monkeys spontaneously walk bipedally on the ground and on rigid horizontal surfaces (e.g. tree limbs) in both natural and captive settings (Fragaszy et al., 2004b). We studied a population of wild capuchin monkeys (Sapajus libidinosus) that has been habituated to human observers and voluntarily performs bipedal locomotion on terrestrial substrates while transporting a heavy load (Visalberghi et al., 2009a; Duarte et al., 2012; Massaro et al., in review). These monkeys crack palm nuts on stone and log anvils (Fragaszy et al., 2004a), and they transport hammer stones to an anvil as needed (Visalberghi et al., 2009b; Visalberghi et al., 2013). Hammer stones used by the monkeys in this region weigh on average about $1 \mathrm{~kg}$ (Visalberghi et al., 2007; Spagnoletti et al., 2011). The mass of these stones is $\sim 25-45 \%$ of an adult capuchin's mass, and these stones are carried with two hands in front of the animals' bodies. This wild population of $S$. libidinosus presents a unique 
opportunity to carry out an integrative study to examine the kinetics of bipedalism during load transport in a non-human primate belonging to a taxonomic group that is primarily arboreal, yet exhibits a range of variation in frequencies of terrestrial substrate use, bipedal behavior, and foraging behaviors that include object manipulation and, as in the case of our study population, tool transport and use. It is worth noting at the outset that the data presented here are limited because the only times in which these animals engaged in bipedalism across the force plate was when they carried a load. Capuchins move bipedally when they are not carrying heavy loads, but they do so unpredictably and thus we could not systematically record bipedal locomotion of unloaded wild monkeys. Thus our data on capuchins carrying a load bipedally will be compared with data collected by other researchers on capuchins that are moving bipedally but not carrying a load (Demes and O'Neill, 2013).

Five members of one wild group of bearded capuchin monkeys voluntarily participated in this study (Table 1). The study site is located in Piauí, Brazil on private property (Fazenda Boa Vista or FBV). Madden et al. (2007) and Visalberghi et al (2009b) provide details of the region. Body masses of the subjects were obtained by the monkeys' voluntary use of a scale as described in Fragaszy et al. (2010; in press). Briefly, an electronic platform scale was mounted to a tree and provisioned with corn kernels. When an animal voluntarily visited the scale and was stationary, a nearby researcher recorded the animal's mass. Average masses from multiple visits by each individual are reported. Adults males in this population weigh 3.4 to $4.4 \mathrm{~kg}$; adult females, 1.7 to $2.2 \mathrm{~kg}$ (Fragaszy et al., 2010).

\footnotetext{
$* * * * * * * * * * * * * * *$ Insert Table $1 * * * * * * * * * * * * * * * *$
} 
The experiments took place during the early dry season in late May 2012. An area that the monkeys were known to frequent was prepared for filming and for embedding the force plate. The site contained several boulders, logs, and exposed stones used by the monkeys as anvils, and several loose stones used as hammers by the monkeys. A quartzite stone weighing $0.93 \mathrm{~kg}$, elliptical in shape, that was frequently used by all the monkeys as a hammer stone was provided for use in this experiment; all other loose stones were removed from the immediate area for the duration of filming, and replaced when the research team left each day. One anvil (a log, $1 \mathrm{~m}$ long, $25 \mathrm{~cm}$ in diameter, with a level surface containing several pits where the monkeys place nuts to crack them; (Fragaszy et al., 2010) was selected for the purposes of this experiment. The monkeys were encouraged to use this anvil and to carry the hammer stone along a linear course by placing the hammer stone and a palm nut (locally collected Orbygnia spp.) $4 \mathrm{~m}$ from the selected anvil (closer to this anvil than any other in the area). The course the monkeys traveled was within 2 degrees of flat and horizontal. The substrate was compacted, sandy soil free of obstructions (Figure 1).

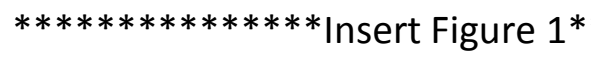

\section{Data collection and analysis}

Halfway between the hammer stone and anvil, a force transducer (MC3A-250; AMTI; Watertown, MA) had been embedded in the ground (see Fig. 1). Briefly, this force transducer utilized strain gauge sensors (versus piezoelectric sensors) and was rated for maximum loads of $556 \mathrm{~N}$ in the $\mathrm{X}$ and $\mathrm{Y}$ directions, and $1112 \mathrm{~N}$ in the $\mathrm{Z}$ direction, with an additional capacity of 28 $\mathrm{N}-\mathrm{m}$ in the $\mathrm{X}$ and $\mathrm{Y}$ moments, and $14 \mathrm{~N}-\mathrm{m}$ in the $\mathrm{Z}$ moments. Crosstalk across the channels was less than $2 \%$. 
The transducer was placed in a hole approximately $50 \mathrm{~cm} \times 25 \mathrm{~cm} \times 40 \mathrm{~cm}$ deep, large enough to accommodate a cement block (10 kg) to which the force transducer was screwed. A 3/4 inch plywood with a rubberized surface (termed "faceplate"), just smaller than the opening of the hole $(\sim 49.5 \mathrm{~cm} \times 24.5 \mathrm{~cm})$, was affixed to the top of the force transducer and camouflaged with a sprinkling of soil. The reliability of this faceplate was tested by placing known mass $(10 \mathrm{~kg})$, two to three times that of the mass of the monkeys and stone, on the edges of the faceplate prior to setup. The moments generated due to the size of the faceplate attached to the force transducer were within the limits of each channel. For any recording in which there was clipping of any of the signals due to the amplifier settings, the trial was not analyzed. Only steps in which a foot was fully in contact with the faceplate were analyzed.

The instrumented surface was level with the ground path of travel between the hammer stone and anvil (this was checked daily). The vertical component of the force output was calibrated daily by placing a known mass on the plate. Force data were recorded at $600 \mathrm{hz}$ using MaxDaq software (Innovision systems, Columbiaville, MI). The force component data were output in volts. The force transducer was a type 2 force plate, thus the sensitivity matrix was used to convert voltage output into Newtons. Filtering was accomplished in Excel using a Visual Basic macro, with a $4^{\text {th }}$ order (two-pass) Butterworth-style filter (Murphy and Robertson, 1994). We used the same cut-off frequency for all directions, as each component force was calculated on the basis of the entire sensitivity matrix, rather than with the single coefficient. A cut-off frequency of $25 \mathrm{hz}$ was determined to be the optimal balance between signal distortion and noise after residual analysis of all three components (Winter, 2005). The concrete block and force transducer were left outside, with the hole they were in being covered each night. Since 
it was the dry season and the transducer was built to be highly water resistant, there was no concern of fluid disrupting the electronics. The amplifier, cable, and A/D converter were attached to the force plate each day and taken in each night.

When a monkey voluntarily approached to retrieve the hammer stone and nut, the recording of the video and force transducer was initiated. The file was saved if the monkey contacted the force plate as it traveled to the anvil. Video recording and digitization methods followed those described in Duarte et al. (2012). We video recorded the movements of each monkey from the moment it picked up the hammer stone through transport to when it reached the anvil. Two video cameras (Canon GL2) running at $30 \mathrm{fps}$ were placed at oblique angles (approximately 60-90 degrees between the cameras) to the expected line of travel of the monkeys. A dynamic wand calibration was performed prior to the experimental session. The videos from both cameras were synchronized by detecting a common event (e.g. heel strike on the force transducer). The video data were used to calculate subject velocity. Only one stride per trial was analyzed for spatiotemporal characteristics. Data processing was performed using MaxMate software (Innovision systems, Columbiaville, MI) for spatiotemporal data. The following variables were calculated from these processed data: speed, contact time, stride time, swing time, duty (contact time/stride time), vertical peak force (Vpk), Vpk as a ratio to total weight (body weight plus stone weight), peak braking, propulsive force, medial and lateral forces both as absolute values and as a ratio of total weight, and vertical, braking, propulsive, and medio-lateral duration and impulse. All values were tested for associations with speed. 


\section{Results}

Table 1 presents sample and body mass data for each subject in this study. Summary descriptive force data for load transport during bipedal locomotion are presented in Table 2. A total of 28 steps were suitable for analysis with complete contact with the force plate and steady-state movement across the plate. Subjects exhibited a wide range of walking speeds from $0.8 \mathrm{~m} / \mathrm{s}$ to $2.0 \mathrm{~m} / \mathrm{s}$. Thus the sample included relatively slow and fast walking gaits. All subjects used walking gaits. No gaits with an aerial phase were included, as these did not occur regularly. The lowest duty factor was 0.5 and the highest was 0.71 . The mean value was 0.63 , and duty factor had an inverse relationship with speed as it does in most primate species as well as in other mammals.

\section{$* * * * * * * * * * * * * * *$ Insert Table $2 * * * * * * * * * * * * * * * *$}

Mean vertical peak force as a ratio to total weight during load transport by bipedal capuchins from this study is 1.185 ( $\mathrm{sd}=0.131$; Table 3 ). Vertical peak force ratios showed a weak positive trend with subject velocity, although this relationship was not significant (Figure 2a, Table 4). Vertical impulse ratios showed no relationship to speed as was also expected (Table 4).

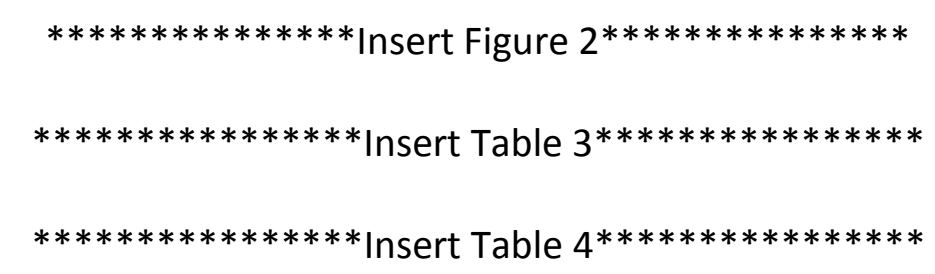

All of the vertical force traces showed only a single peak (the "triangular form" described by Kimura et al. (1977)) and $85 \%$ (24 of 28 steps) of the traces examined had a measurable impact peak (transient impact spike) at foot contact (Figure 3a). On average, the 
peak of the impact spike was $89 \%$ of total weight, with none exhibiting a value less than $52 \%$ of total weight (when present). The presence of an impact spike at foot contact is a consistent and significant pattern in these capuchin monkeys walking with load.

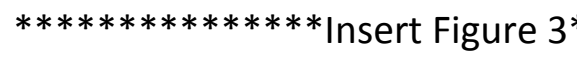

Braking propulsive forces oscillated in a fashion that was consistent with forward progression in all bipedal animals. However, braking duration was shorter than propulsive duration (Figure 3b), exhibiting the typical pattern reported by Kimura et al. (1977) for many nonhuman primates including chimpanzees, gibbons, Japanese macaques, hamadryas baboons, and spider monkeys. Propulsive impulses increase with speed and braking impulses decrease with speed at a shallower rate (Fig. 2b). At relatively low speeds braking and propulsive impulses are near equal (Fig. 2b). As speed increases, however, braking and propulsive impulses diverge, suggesting that at higher speeds some subjects may have been accelerating.

All subjects applied a lateral force to the ground (i.e. the outward force of Kimura et al. (1977), which was found in all species studied including humans; Figure 3c). The lateral impulse decreases dramatically with speed (Figure $2 b$ ). On some occasions the animals applied a medial force during stance (Figure 3c; a pattern also reported for some animals by Kimura et al. (1977). When present, the medial impulse is always low and increases slightly with speed (Fig. 2b). This relationship between speed and force is also reflected in the normalized medio-lateral peak forces. Both lateral peak forces and medial (when present) peak forces decrease with speed (Fig. 2a). 


\section{Discussion}

Primate locomotor evolution is characterized by a series of shifts in the relative role of the forelimbs and hindlimbs, with brachiation and obligate bipedalism being powerful examples of extreme shifting of the responsibility of locomotion to the forelimb or the hindlimb respectively (see Stern, 1976; Schmitt, 2012; Fleagle, 2013). To date, there exists no uniformly accepted theory about what selective pressures drove the evolution of obligate bipedalism. One factor, load carriage, has been argued to be either a key selective factor in the origins of obligate bipedalism or at least a valuable advantage gained from the adoption of bipedalism, even facultatively (e.g. Hewes, 1961; Videan and McGrew, 2002; Carvalho et al., 2013). The study presented here is the first to examine the biomechanics of naturally occurring bipedal locomotion during load carriage in a nonhuman primate in order to explore the relationship between load carriage and patterns of forces on the lower limb. Of course, it would be difficult to resolve this issue with only the data presented here, but they do enable the direct examination of ways in which load carriage influences bipedal locomotion and help to determine whether the pattern observed in capuchins has similarities to that of unloaded nonhuman primates and humans. Thus, we describe the similarities and differences between the data in this study and previous work for each force component.

\section{Vertical Component}

The data collected here show that vertical forces recorded during bipedalism of capuchins carrying a load reflect force patterns similar to that recorded for other non-human primate species that use bipedal locomotion. For example, in 1977 and 1979, Kimura and colleagues described the triangular-shaped vertical force curves and short braking periods that 
characterize, with the exception of humans and chimpanzees, bipedal locomotion in primates. More recently, Demes and O'Neill (2013) described vertical peak force and curve shape in unloaded bipedal capuchins (S. apella spp.) walking in the laboratory. The capuchins in the present study are walking at comparable speeds and have peak forces for all three components of the ground reaction force normalized to body weight similar to all the species reported by Kimura et al. (1977) and those of Demes and O'Neill (2013). The capuchins studied here match Kimura et al.'s (1977) "type 1" form with the single-peak force curve and relatively short braking duration. The single-peaked force curve, also reported by Demes and O'Neill (2013), appears to reflect the use of a relatively compliant hindlimb (Li et al., 1996; Schmitt, 1999; Demes and O'Neill, 2013). The data, therefore, suggest that load carriage does not change the relative stiffness of the lower limb compared to unloaded bipedal walking. Load carriage, at least in these primates, does not induce human-like walking with a relatively unyielding knee.

The capuchins in this study, however, differ from other nonhuman primate bipeds in a key way. The majority (85\%) of steps recorded during load carriage in this sample showed the presence of a substantial vertical impact spike, suggesting a forceful foot contact at relatively high velocity, like that seen in humans (Voloshin et al., 1981; Chi and Schmitt, 2005; Lieberman et al., 2010). Such a spike is not regularly seen in any of the vertical force traces for any of the nonhuman primate bipeds included in the Kimura et al. studies $(1977,1979)$ or in the chimpanzees examined by Kimura (1985), or even in the steps recorded for the trained macaques studied by Ogihara et al. (2007). Demes and O'Neill (2013) also report that their vertical force traces did not have the impact spike that is typical of human walking and running. The only study to report such an impact transient in bipedal, nonhuman primates is Pontzer et 
al. (2014); only some of their subjects exhibited this transient, whereas all five of our subjects exhibited it. The presence of an impact spike is generally attributed to the rapid change of momentum associated with high vertical velocities of the foot and loading rates associated with heel strike (Lieberman et al., 2010). During extended limb load transport in humans, an increase in the magnitude of the impact spike has been reported, even with light loads (Birrell and Haslam, 2008). While the monkeys in this study did not exhibit heel strike, they did have an impact spike in most steps and likely experienced higher rates of initial loading on their lower limb due to the increase in mass caused by load transport. These impact spikes are thought to be a source of both injury and degeneration in the lower limb of modern humans (Voloshin et al., 1981; Lieberman et al., 2010). If load carriage induced such impact spikes in early hominins they may have needed to develop behavioral and/or anatomical mechanisms to compensate for this relatively high and rapidly applied load.

\section{Braking/Propulsive and Medio-lateral Components}

Our study subjects alternated between braking and propulsive forces to decelerate and accelerate the center of mass. The braking/propulsive and medio-lateral forces showed predictable patterns with speed reflecting acceleration at high speeds in the former and decreased need for stabilization in the latter as dynamic stability increased with increasing speeds. The capuchins studied here applied lateral forces to the ground to control side-to-side movements of the center of mass.

In this study, as Kimura and colleagues $(1977,1979)$ also reported, there is substantial variability in the magnitude and shape of medio-lateral forces. One source of variation is subject velocity, though it explains a relatively small portion of the variance (Table 4). We did 
observe that lateral peak forces and impulses drop substantially with speed, narrowing the range of force values at higher speeds. As a result, a large portion of the extreme values for lateral forces occur at low speed and lateral peak and impulse force decreased with increased speed (Fig. 2b). Variation in medio-lateral force magnitude also decreased with increased speed. This suggests the possibility that at higher speeds capuchins achieve a level of dynamic stability with minimal side-to-side oscillations, like a bicycle or coin rolling quickly that requires fewer applied forces. It is possible that early attempts at bipedalism, especially during load carriage, required the least effort for side-to-side stabilization at relatively high walking speeds.

Although caution is warranted in using data in this study to address the exact selective pressures driving the evolution of bipedalism, we can consider how load carriage impacts the pathway of locomotor and morphological evolution. It would appear from these data that the addition of a manual task and load carriage is associated with changes in limb mechanics and loading patterns that could impact anatomy. Studies like these that include data from movement that is not only associated with locomotor travel, but rather, as in this case, travelling with a load, provide important data and context for form-function inferences in the primate skeleton. Similarly, load patterns during pregnancy and infant carriage should be further explored in the same context to understand better the loading patterns for limb bones in primates (e.g. Wall-Scheffler et al., 2007a).

\section{Conclusions}

This study provides the first kinetic data on primate facultative bipedalism during load transport in a wild setting. It has integrated both laboratory and field methods to permit such data collection and in doing so, has not just metaphorically moved "the force plate...into the 
field" (Schmitt, 2011: 8), but actually placed one there. Future work with this and other populations will permit a better understanding of the complexity of locomotion as it relates to morphology by permitting data collection in the field. The primary findings in this study confirm that grounded running gaits characterize locomotion of capuchins both with and without loads and that load carrying does not induce a change in lower limb stiffness. But the animals in this study showed a clear impact spike at foot contact, a pattern not reported for any other nonhuman primate or in capuchins not carrying a load. This finding suggests that load carriage may increase landing forces and generate a measurable impact spike that would have an impact on lower limb anatomy in the earliest hominin bipeds.

\section{Acknowledgements}

We thank the Oliveira family for allowing the EthoCebus research group to work on their land and for logistical assistance and Dr. Andrew Thompson for helpful comments on this manuscript. This research is supported by grants from the National Geographic Society (How Others Help Young Wild Bearded Capuchin Monkeys (Cebus Libidinosus) Learn to Crack Nuts With Stone Tools), NSF (BCS-0749314) and the L.S.B. Leakey Foundation (How bearded capuchin monkeys process cashew nuts). None of the authors has any conflict of interest to declare. 


\section{References}

Aerts, P., Van Damme, R., Van Elsacker, L., Duchene, V., 2000. Spatio-temporal gait characteristics of the hind-limb cycles during voluntary bipedal and quadrupedal walking in bonobos (Pan paniscus). Am. J. Phys. Anthropol. 111, 503.

Alfaro, J.W.L., Silva, J.D.E., E., S., Rylands, A.B., 2012. How different are robust and gracile capuchin monkeys? An argument for the use of Sapajus and Cebus. Am. J. Primtol. 74, 273-286.

ASAB, 2012. Guidelines for the treatment of animals in behavioural research and teaching. Anim Behav. 83, 301-309.

Berillon, G., D'Aout, K., Daver, G., Dubreuil, G., Multon, F., Nicolas, G., De La Villetanet, B., 2011. In what manner do quadrupedal primates walk on two legs? Preliminary results on olive baboons (Papio anubis), Primate Locomotion: Linking Field and Laboratory Research. Springer, New York, pp. 61-82.

Berillon, G., Vila, P.M., Lacoste, R., Rimbaud, B., Anvari, Z., D'Aout, K., Dussea, S.M., Moulin, V., 2013. Biomechanics and control of walking in olive baboons (Papio anubis): new perspectives from trained and instrumented animals. Folia Primatol. 84, 249-249.

Birrell, S.A., Haslam, R.A., 2008. The influence of rifle carriage on the kinetics of human gait. Ergonomics. 51, 816-826.

Birrell, S.A., Hooper, R.H., Haslam, R.A., 2007. The effect of military load carriage on ground reaction forces. Gait Posture. 26, 611-614.

Cant, J.G.H., 1988. Positional behavior of long-tailed macaques (Macaca fascicularis) in northern Sumatra. Am. J. Phys. Anthropol. 76, 29-37. 
Carvalho, S., Biro, D., Cunha, E., Hockings, K., McGrew, W.C., Richmond, B.G., Matsuzawa, T., 2013. Chimpanzee carrying behaviour and the origins of human bipedality. Curr. Biol. 22, R180-R181.

Chi, K.-J., Schmitt, D., 2005. Mechanical energy and effective foot mass during impact loading of walking and running. J. Biomech. 38, 1387-1395.

D’Août, K., Aerts, P., Berillon, G., 2014. Using primate models to study the evolution of human locomotion: concepts and cases. BMSAP. 26, 105-110.

Daver, G., Détroit, F., Berillon, G., Prat, S., Grimaud-Hervé, D., 2014. Fossil hominins, quadrupedal primates and the origin of human bipedalism: a 3D geometric morphometric analysis of the Primate hamate. BMSAP. 26, 121-128.

Demes, B., 2011. Three-dimensional kinematics of capuchin monkey bipedalism. Am. J. Phys. Anthropol. 145, 147-155.

Demes, B., O'Neill, M.C., 2013. Ground reaction forces and center of mass mechanics of bipedal capuchin monkeys: implications for the evolution of human bipedalism. Am. J. Phys. Anthropol. 150, 76-86.

Duarte, M., Hanna, J.B., Sanches, E., Liu, Q., Fragaszy, D., 2012. Kinematics of bipedal locomotion while carrying a load in the arms in bearded capuchin monkeys (Sapajus libidinosus). J. Hum. Evol. 63, 851-858.

Fleagle, J.G., 2013. Primate Adaptation and Evolution, 3rd ed. Academic Press.

Fragaszy, D., Izar, P., Liu, Q., Eshchar, Y., Young, L., Visalberghi, E., in press. Body mass in wild bearded capuchins (Sapajus libidinosus): Ontogeny and sexual dimorphism. Am J Primatol. 
Fragaszy, D., Izar, P., Visalberghi, E., Ottoni, E.B., de Oliveira, M.G., 2004a. Wild capuchin monkeys (Cebus libidinosus) use anvils and stone pounding tools. Am. J. Primatol. 64, 359-366.

Fragaszy, D., Pickering, T., Liu, Q., Izar, P., Ottoni, E., Visalberghi, E., 2010. Bearded capuchin monkeys' and a human's efficiency at cracking palm nuts with stone tools: field experiments. Anim. Behav. 79, 321-332.

Fragaszy, D.M., Visalberghi, E., Fedigan, L.M., 2004b. The complete capuchin: the biology of the genus Cebus. Cambridge University Press.

Gebo, D.L., 1987. Locomotor diversity in prosimian primates. Am. J. Primatol. 13, 271-281.

Griffin, T.M., Roberts, T.J., Kram, R., 2003. Metabolic cost of generating muscular force in human walking: insights from load-carrying and speed experiments. J. Appl. Physiol. 95, $172-183$.

Hewes, G.W., 1961. Food transport and the origin of hominid bipedalism. Amer. Anthropol. 63, 687-710.

Hsiang, S.M., Chang, C., 2002. The effect of gait speed and load carrying on the reliability of ground reaction forces. Safety Sci. 40, 639-657.

Hunt, K.D., 1991. Positional behavior in the Hominoidea. Int. J. Primatol. 12, 95-118.

IPS, 2015. Protection of primate health in the wild. International Primatological Society. http://www.internationalprimatologicalsociety.org/ProtectionOfPrimateHealthInTheWil d.cfm. May 5, 2015. 
Kimura, T., 1985. Bipedal and quadrupedal walking of primates: comparative dynamics, in:

Kondo, S. (Ed.), Primate Morphophysiology: Locomotor Analyses and Human Bipedalism. University of Tokyo press, Tokyo, pp. 81-104.

Kimura, T., Okada, M., Ishida, H., 1977. Dynamics of primate bipedal walking as viewed from the force of foot. Primates. 18, 137-147.

Kimura, T., Okada, M., Ishida, H., 1979. Kinesiological characteristics of primate walking: its significance in human walking, in: Morbeck, M.E., Preuschoft, H., Gomberg, N. (Eds.), Environment, Behavior, and Morphology: Dynamic Interactions in Primates. Gustav Fischer, New York, pp. 297-311.

Li, Y., Crompton, R.H., Alexander, R.M., Günther, M.M., Wang, W.J., 1996. Characteristics of ground reaction forces in normal and chimpanzee-like bipedal walking by humans. Folia Primatol. 66, 137-159.

Li, Y., Wang, W.J., Crompton, R.H., Gunther, M.M., 2001. Free vertical moments and transverse forces in human walking and their role in relation to arm-swing. J. Exp. Biol. 204, 47-58.

Lieberman, D.E., Venkadesan, M., Werbel, W.A., Daoud, A.I., D'Andrea, S., Davis, I.S., Mang'Eni, R.O., Pitsiladis, Y., 2010. Foot strike patterns and collision forces in habitually barefoot versus shod runners. Nature. 463, 531-535.

Madden, M., Fragaszy, D.M., Izar, P., Hinley, A.J., Ottoni, E.B., Visalberghi, E., 2007. Modelling the monkey habitat in Brazil. Geospat. Tod. 5, 26-35.

Majumdar, D., Pal, M.S., Majumdar, D., 2010. Effects of military load carriage on kinematics of gait. Ergonomics. 53, 782-791. 
Massaro, L., Massa, F., Simpson, K.J., Fragaszy, D., Visalberghi, E., in review. Wild capuchins (Sapajus libidinosus) maintain balance while carrying a load bipedally: the strategic role of the tail. Am. J. Primatol.

McGill, S.M., Marshall, L., Andersen, J., 2013. Low back loads while walking and carrying: comparing the load carried in one hand or in both hands. Ergonomics. 56, 293-302.

Murphy, S., Robertson, D., 1994. Construction of a high-pass digital filter from a low-pass digital filter. JAB. $10,374-381$.

Nakatsukasa, M., Ogihara, N., Hamada, Y., Goto, Y., Yamada, M., Hirakawa, T., Hirasaki, E., 2004. Energetic costs of bipedal and quadrupedal walking in Japanese macaques. Am. J. Phys. Anthropol. 124, 248-256.

Ogihara, N., Hirasaki, E., Kumakura, H., Nakatsukasa, M., 2007. Ground-reaction-force profiles of bipedal walking in bipedally trained Japanese monkeys. J. Hum. Evol. 53, 302-308.

Ogihara, N., Makishima, H., Nakatsukasa, M., 2010. Three-dimensional musculoskeletal kinematics during bipedal locomotion in the Japanese macaque, reconstructed based on an anatomical model-matching method. 58, 252-261.

Pontzer, H., Raichlen, D.A., Rodman, P.S., 2014. Bipedal and quadrupedal locomotion in chimpanzees. $66,64-82$.

Preuschoft, H., 2004. Mechanisms for the acquisition of habitual bipedality: are there biomechanical reasons for the acquisition of upright bipedal posture? J. Anat. 204, 363384.

Reynolds, T.R., 1985. Mechanics of increased support of weight by the hindlimbs in primates. Am. J. Phys. Anthropol. 67, 335-349. 
Schmitt, D., 1999. Compliant walking in primates. J. Zool. 248, 149-160.

Schmitt, D., 2003. Insights into the evolution of human bipedalism from experimental studies of humans and other primates. J. Exp. Biol. 206, 1437-1448.

Schmitt, D., 2011. Translating primate locomotor biomechanical variables from the laboratory to the field, in: D/Aout, K., Vereecke, E.E. (Eds.), Primate Locomotion: Linking Field and Laboratory Research. Springer, New York, pp. 7-27.

Schmitt, D., 2012. Primate locomotor evolution: Biomecahnical studies of primate locomotion and their implications for understanding primate neuroethology, in: Platt, M.L., Ghazanfar, A.A. (Eds.), Primate Neuroethology. Oxford Univeristy Press, Oxford, pp. 3163.

Spagnoletti, N., Visalberghi, E., Ottoni, E., Izar, P., Fragaszy, D., 2011. Stone tool use by adult wild bearded capuchin monkeys (Cebus libidinosus). Frequency, efficiency and tool selectivity. J. Hum. Evol. 61, 97-107.

Stern, J.T.J., 1976. Before bipedality. Yrbk. Phys. Anthropol. 19, 59-68.

Tilbury-Davis, D.C., Hooper, R.H., 1999. The kinetic and kinematic effects of increasing load carriage upon the lower limb. Hum. Movement Sci. 18, 693-700.

Tuttle, R.H., 1981. Evolution of Hominid Bipedalism and Prehensile Capabilities. Philos. T. Roy. Soc. B. $292,89-94$.

Tuttle, R.H., Basmajian, J.V., Ishida, H., 1979. Activities of pongid thigh muscles during bipedal behavior. Am. J. Phys. Anthropol. 50, 123-135.

Umberger, B.R., 2008. Effects of suppressing arm swing on kinematics, kinetics, and energetics of human walking. J. Biomech. 41, 2575-2580. 
Vereecke, E., D'Août, K., Van Elsacker, L., De Clercq, D., Aerts, P., 2005. Functional analysis of the gibbon foot during terrestrial bipedal walking: Plantar pressure distributions and three-dimensional ground reaction forces. Am. J. Phys. Anthropol. 128, 659-669.

Vereecke, E.E., Aerts, P., 2008. The mechanics of the gibbon foot and its potential for elastic energy storage during bipedalism. J. Exp. Biol. 211, 3661-3670.

Vereecke, E.E., D'Août, K., Aerts, P., 2006. The dynamics of hylobatid bipedalism: evidence for an energy-saving mechanism? J. Exp. Biol. 209, 2829-2838.

Videan, E.N., McGrew, W.C., 2002. Bipedality in chimpanzee (Pan troglodytes) and bonobo (Pan paniscus): testing hypotheses on the evolution of bipedalism. Am. J. Phys. Anthropol. $118,184-190$.

Visalberghi, E., Addessi, E., Truppa, V., Spagnoletti, N., Ottoni, E., Izar, P., Fragaszy, D., 2009a. Selection of effective stone tools by wild bearded capuchin monkeys. Curr. Biol. 19, 213-217.

Visalberghi, E., Fragaszy, D., Ottoni, E., Izar, P., de Oliveira, M.G., Andrade, F.R.D., 2007.

Characteristics of hammer stones and anvils used by wild bearded capuchin monkeys (Cebus libidinosus) to crack open palm nuts. Am. J. Phys. Anthropol. 132, 426-444.

Visalberghi, E., Haslam, M., Spagnoletti, N., Fragaszy, D., 2013. Use of stone hammer tools and anvils by bearded capuchin monkeys over time and space: construction of an archeological record of tool use. J. Archaeol. Sci. 40, 3222-3232.

Visalberghi, E., Spagnoletti, N., da Silva, E.D.R., Andrade, F.R.D., Ottoni, E., Izar, P., Fragaszy, D., 2009b. Distribution of potential suitable hammers and transport of hammer tools and nuts by wild capuchin monkeys. Primates. 50, 95-104. 
Voloshin, A., Wosk, J., Brull, M., 1981. Force wave transmission through the human locomotor system. J. Biomech. Eng. 103, 48-50.

Wall-Scheffler, C., Geiger, K., Steudel-Numbers, K., 2007a. Infant carrying: the role of increased locomotory costs in early tool development. $133,841-846$.

Wall-Scheffler, C.M., Geiger, K., Steudel-Numbers, K.L., 2007b. Infant carrying: the role of increased locomotory costs in early tool development. Am. J. Phys. Anthropol. 133, 841846.

Wang, W.J., Crompton, R.H., 2004. The role of load-carrying in the evolution of modern body proportions. J. Anat. 204, 417-430.

Wang, W.J., Crompton, R.H., Wood, C.G., Li, Y., Gunther, M.M., 2002. Kinematics and kinetics of the joints of the lower limb during normal and bent-knee loaded walking, in: Ujihashi, S., Hakke, S. (Eds.), The Engineering of Sport. Blackwell, London, pp. 739-747.

Watson, J., Payne, R., Chamberlain, A., Jones, R., Sellers, W., 2011. The Influence of Load Carrying on Gait Parameters in Humans and Apes: Implications for the Evolution of Human Bipedalism, in: D'Août, K., Vereecke, E.E. (Eds.), Primate Locomotion. Springer New York, pp. 109-134.

Watson, J., Payne, R., Chamberlain, A., Jones, R., Sellers, W.I., 2009. The kinematics of load carrying in humans and great apes: implications for the evolution of human bipedalism. Folia Primatol. 80, 309-328.

Watson, J.C., Payne, R.C., Chamberlain, A.T., Jones, R.K., Sellers, W.I., 2008. The energetic costs of load-carrying and the evolution of bipedalism. J. Hum. Evol. 54, 675-683. 
Winter, D.A., 2005. Biomechanics and motor control of human movement, 3rd ed. John Wiley \& Sons.

Wright, K.A., Wright, B.W., Ford, S.M., Fragaszy, D., Izar, P., Norconk, M.A., Masterson, T., Hobbs, D.G., Alfaro, M.E., Lynch Alfaro, J.W., 2015. The effects of ecology and evolutionary history on robust capuchin morphological diversity. Mol. Phylogenet. Evol. 82, Part B, 455-466.

Wunderlich, R.E., Tongen, A., Gardiner, J., Miller, C.E., Schmitt, D., 2014. Dynamics of Locomotor Transitions from Arboreal to Terrestrial Substrates in Verreaux's Sifaka (Propithecus verreauxi). Integr. Comp. Biol.

Yamazaki, N., Ishida, H., Kimura, T., Okada, M., 1979. Biomechanical analysis of primate bipedal walking by computer simulation. J. Hum. Evol. 8, 337-349.

\section{Figure captions}

Figure 1. Photograph of the force transducer hole $(A)$ and a schematic of a monkey walking from the retrieval of the hammer stone and nut towards the anvil (B).

Figure 2. Regression of forces as a ratio to total weight against speed. Trend lines are leastsquares regressions. Braking/propulsive lines of best fit are paired as solid, with different shades. Medio-lateral lines of best fit are paired as dashed with different shades. The Y-axes are dimensionless. A. Peak hind limb force for bipedalism as a ratio to total weight (stone included). B. Impulse hind limb force for bipedalism as a ratio to total weight (stone included). 
Figure 3. Summary component force data for each subject. Two subjects (Piassava and ChuChu) were not included because they each had just one trace and these included an additional partial limb, or the entire trace was not captured. Gray, dotted lines indicate each trial. Solid black line is the average value for all trails over the time period calculated using a cubic spline. Stance phase was normalized for each trial and presented as a percent of total stance (0-100\%). The Y-axes are dimensionless. A. Vertical component B. Braking/Propulsive component C. Medio-lateral component. 
Table 1. Sample size for individual monkeys

\begin{tabular}{|l|c|c|c|}
\hline Subject & Body mass (kg) & Steps & Steps with \\
& & & impact peak \\
\hline Dita & 2.03 & 11 & 9 \\
\hline Jatoba & 4.12 & 12 & 12 \\
\hline Pati & 2.02 & 3 & 1 \\
\hline Piassava & 1.86 & 1 & 1 \\
\hline Chuchu & 1.97 & 1 & $\mathbf{2 4}$ \\
\hline Sum & & $\mathbf{2 8}$ & \\
\hline
\end{tabular}


Table 2. Spatiotemporal data during bipedal load transport by capuchin monkeys. Total weight is the animal's body weight plus the weight of the stone.

\begin{tabular}{|c|c|c|c|c|}
\hline & Mean & SD & Max & Min \\
\hline Speed (m/s) & 1.301 & 0.285 & 2.079 & 0.817 \\
\hline Contact Time (sec) & 0.287 & 0.039 & 0.333 & 0.200 \\
\hline Stride time (sec) & 0.455 & 0.040 & 0.533 & 0.367 \\
\hline Swing time (sec) & 0.168 & 0.025 & 0.233 & 0.133 \\
\hline Duty factor & 0.630 & 0.054 & 0.714 & 0.500 \\
\hline Body mass (kg) & 2.916 & 1.062 & 4.120 & 1.860 \\
\hline Total weight (including stone) (N) & 37.695 & 10.407 & 49.490 & 27.342 \\
\hline
\end{tabular}


Table 3. Summary descriptive force data during bipedal load transport by capuchin monkeys.

All data are presented as dimensionless force relative to total weight (animal's weight plus stone weight).

\begin{tabular}{|c|c|c|c|c|}
\hline & Mean & SD & Max & Min \\
\hline Impulse braking force & 0.009 & 0.005 & 0.023 & 0.000 \\
\hline Impulse propulsion force & 0.015 & 0.007 & 0.030 & 0.002 \\
\hline Impulse lateral force & 0.004 & 0.004 & 0.020 & 0.000 \\
\hline Impulse medial force & 0.011 & 0.008 & 0.026 & 0.001 \\
\hline Impulse vertical force & 0.196 & 0.029 & 0.245 & 0.140 \\
\hline Peak braking force & 0.160 & 0.055 & 0.281 & 0.036 \\
\hline Peak propulsion force & 0.199 & 0.087 & 0.050 & 0.396 \\
\hline Peak lateral force & 0.080 & 0.047 & 0.213 & 0.020 \\
\hline Peak medial force & 0.074 & 0.050 & 0.003 & 0.186 \\
\hline Peak vertical force & 1.185 & 0.131 & 1.409 & 0.925 \\
\hline Peak impact force & 0.893 & 0.154 & 1.112 & 0.525 \\
\hline
\end{tabular}


Table 4. Least squares regression parameter estimates, standard errors (s.e.) and probability ( $p$ value) of variables on speed. Bold values indicate significance.

\begin{tabular}{|c|c|c|c|c|c|c|c|c|c|c|c|c|c|c|}
\hline & \multicolumn{7}{|c|}{ Peak force as a ratio to total weight } & \multicolumn{7}{|c|}{ Impulse force as a ratio to total weight } \\
\hline & Intercept & s.e. & p value & Slope & s.e. & $p$ value & $\mathbf{R}^{2}$ & Intercept & s.e. & $p$ value & Slope & s.e. & $p$ value & $\mathbf{R}^{2}$ \\
\hline Vertical & 1.011 & 0.115 & $<0.001$ & 0.133 & 0.086 & 0.135 & 0.084 & 0.208 & 0.027 & $<0.001$ & -0.009 & 0.021 & 0.672 & 0.008 \\
\hline Braking & -0.092 & 0.077 & 0.242 & -0.082 & 0.058 & 0.166 & 0.0743 & 0.011 & 0.006 & 0.075 & -0.001 & 0.004 & 0.815 & 0.003 \\
\hline Propulsive & 0.062 & 0.045 & 0.191 & 0.075 & 0.035 & 0.041 & 0.152 & 0.008 & 0.006 & 0.207 & 0.005 & 0.005 & 0.330 & 0.041 \\
\hline Medial & 0.148 & 0.040 & 0.001 & -0.052 & 0.030 & 0.097 & 0.102 & -0.002 & 0.004 & 0.707 & 0.004 & 0.003 & 0.185 & 0.082 \\
\hline Lateral & 0.019 & 0.042 & 0.658 & -0.072 & 0.032 & 0.033 & 0.164 & 0.028 & 0.007 & $<0.001$ & -0.013 & 0.005 & 0.016 & 0.237 \\
\hline
\end{tabular}



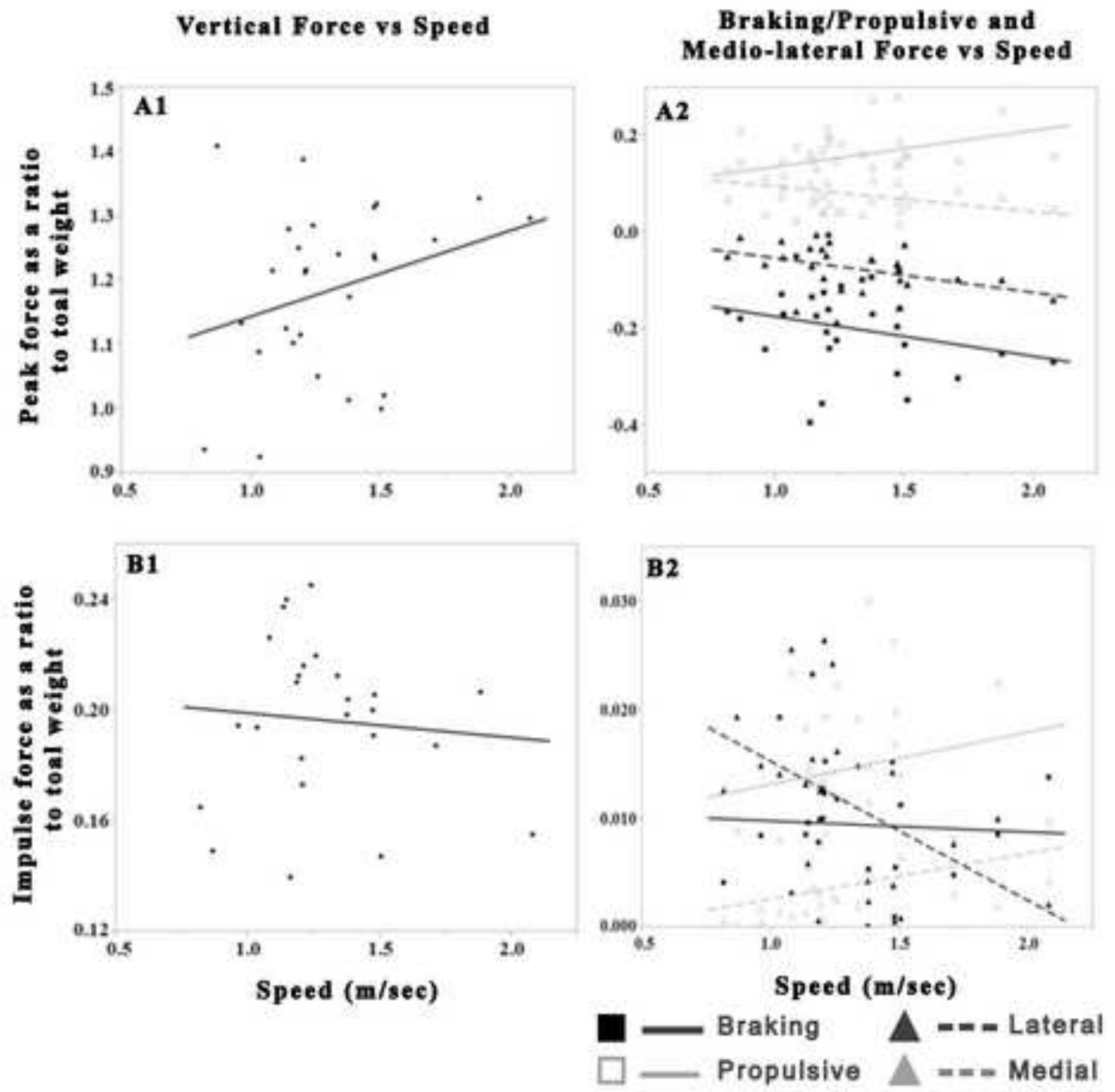

Figure 2 Force vs speed 
Figure 3 Force traces by subject
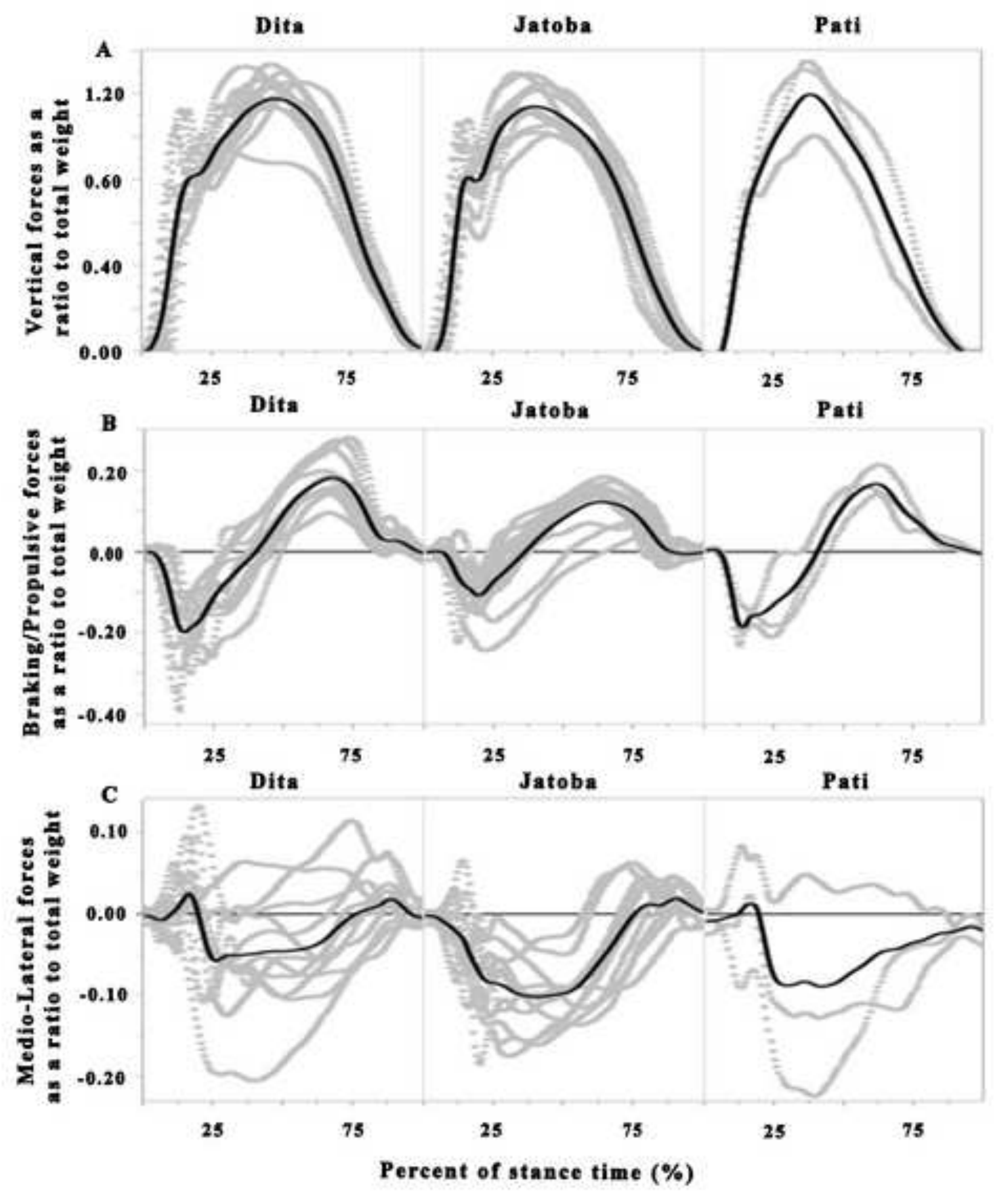